\title{
Use of sequential case-control studies to investigate a community salmonella outbreak in Wales
}

\author{
Lise J Llewellyn, Meirion R Evans, Stephen R Palmer
}

\begin{abstract}
Study objective-To establish the source of a community outbreak of Salmonella typhimurium definitive type 124 . Design-Two stage case-control study. Setting-Three districts in south east Wales.

Subjects-Cases of salmonella food poisoning and community controls.

Main results-An initial case-control study identified an association between illness and eating ham (odds ratio 4.50, $95 \%$ confidence intervals $1.10,21.8)$ and also found a possible association between illness and food bought from delicatessen stores (odds ratio $5.03,95 \%$ confidence intervals 1.01, 32.3). However, only after a second stage case-control study was a single common ham producer identified as the source (odds ratio $25.0,95 \%$ confidence intervals $2.33,1155$ ).

Conclusion-Sequential case-control studies are an important and underused tool in the investigation of community outbreaks.
\end{abstract}

(F Epidemiol Community Health 1998;52:272-276)

Public health investigations of foodborne disease outbreaks are often unsuccessful: the vehicle of infection was traced in only 170 of $342(50 \%)$ of salmonella outbreaks in the US between 1983-1987, ${ }^{1}$ and in only 124 of 272 (46\%) salmonella outbreaks in England and Wales between 1992-93. ${ }^{2}$ Several aspects of foodborne disease outbreaks present difficulties in investigation. Firstly, cluster identification and outbreak recognition may be delayed because the pathogen is a common isolate. Secondly, the vehicle of infection may be a food commonly eaten by both cases and controls and the source not easily identified unless precise details (for example, brand, batch number, supplier) are elicited. Thirdly, cases may be geographically scattered hampering both early cluster identification and coordination of investigation and finally, delay in investigation may lead to recall bias and problems obtaining food for microbiological examination.

Case-control studies are particularly suited for investigating outbreaks and where they have been used routinely, success rates have been high. ${ }^{34}$ This is because they are efficient; they can be used where the population at risk cannot be clearly defined; they allow multiple aetiological hypotheses to be tested concurrently; and they permit interim data analysis. ${ }^{5}$
Sometimes, however, sequential case-control studies may be necessary to clarify and refine the hypothesis. The case-control method allows case definitions to be refined to improve specificity, and hypotheses about risk factors to be formulated and tested in an adaptive and sequential process.

In 1992, a geographically scattered outbreak of Salmonella typhimurium definitive type (DT) 124 occurred in south east Wales. We highlight the value of a sequential case-control study method in tracking down the source to a single ham producer and bringing the investigation to a successful conclusion.

\section{Methods}

In mid June 1992, the Laboratory of Enteric Pathogens of the Public Health Laboratory Service reported a cluster of isolates of Salmonella typhimurium definitive type (DT) 124 identified through its total laboratory surveillance system. ${ }^{6}$ Eighteen reports were from laboratories in south east Wales, including 16 recorded during May, compared with only one other isolate from the remainder of the United Kingdom during the previous six months. $S$ typhimurium DT 124 is rare in the United Kingdom and only one outbreak has ever been reported, resulting from contaminated imported salami sticks. ${ }^{7}$

All microbiology laboratories in Wales were alerted to the incident using the electronic network EPINET, ${ }^{8}$ and requested to report all suspected $S$ typhimurium isolates to the outbreak control team. Preliminary face to face interviews were conducted with 12 cases using a trawling questionnaire and information sought on date of onset of illness, foods eaten in the three days before illness, and general food preferences. Any history of recent foreign travel was also noted. Two sequential case-controls studies were subsequently performed-the first during the final week of June and the second during the initial fortnight of July.

The first case-control study was undertaken to test the hypothesis generated by the initial investigation that illness was associated with the consumption of ham from a local store. A case was defined as a person living in south east Wales with a faecal isolate of $S$ typhimurium DT 124 since 1 April 1992. Secondary cases (household contacts in whom the onset of illness was 24 hours after the onset of illness in the first household case) were excluded from the case-control study. For each case, two people registered with the same general practitioner were selected as controls from each 


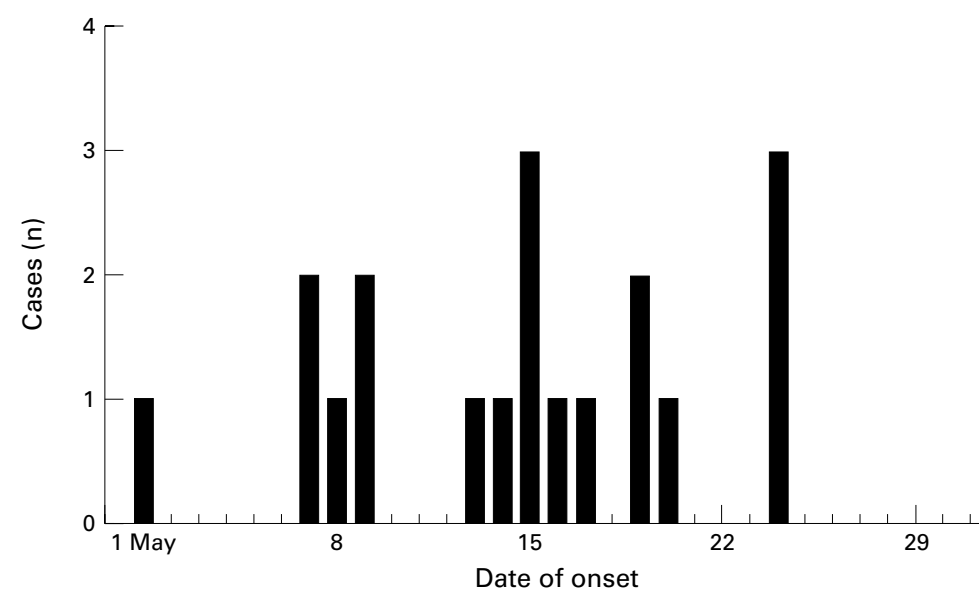

Figure 1 Epidemic curve for 20 cases affected by a Salmonella typhimurium outbreak in south east Wales, 1992 (one case was unable to recall onset date).

practice's age-sex register. Controls were matched for age (adults within 5 years and children within 2 years) and sex (adults only) and selected by taking the next two patients listed on the practice register who met the criteria. Controls with gastrointestinal illness or a history of recent travel abroad were excluded. Interviews were conducted by telephone using a standard, structured questionnaire. Subjects not contactable on the telephone were visited and interviewed at home. Information was elicited on recent gastrointestinal illness and food eaten in the three days before illness (or the same three day period in the matched controls). Subjects were asked specifically about consumption of a range of meat (including cold meats), poultry and dairy products, and about details of brand name, date, and place of purchase.

The second case-control study was performed to obtain more details on ham eaten by cases and controls, to retrace the food chain, and to determine the source of the ham. Subjects were enrolled in the second casecontrol study if they had eaten cold sliced ham in the three days before onset of illness. In addition, investigators visited each of the retail stores from which subjects had purchased ham and used a questionnaire to obtain information from store managers about sources of ham and

Table 1 Case-control study 1. Association between illness and foods eaten by cases and controls in a salmonella outbreak in south east Wales, 1992

\begin{tabular}{|c|c|c|c|c|c|c|}
\hline \multirow[b]{2}{*}{ Food item } & \multicolumn{2}{|c|}{ Case $(n=20)$} & \multicolumn{2}{|c|}{ Control $(n=34)$} & \multirow{2}{*}{$\begin{array}{l}\text { Odds ratio }(95 \% \\
\text { CI) }\end{array}$} & \multirow[b]{2}{*}{$p$ Value } \\
\hline & Ate & Not ate & Ate & Not ate & & \\
\hline Home cooked chicken & 11 & 9 & 22 & 12 & $0.67(0.19,2.40)$ & 0.68 \\
\hline Any cold meat product & 18 & 2 & 19 & 15 & $7.11(1.30,70.4)$ & 0.02 \\
\hline Sliced ham & 16 & 4 & 16 & 18 & $4.50(1.10,21.8)$ & 0.04 \\
\hline Sliced turkey & 4 & 16 & 4 & 29 & $1.81(0.29,11.1)$ & $0.46^{\star}$ \\
\hline Corned beef & 2 & 18 & 10 & 23 & $0.26(0.02,1.46)$ & $0.10^{\star}$ \\
\hline Sliced chicken & 3 & 17 & 4 & 29 & $1.28(0.17,8.55)$ & $1.00^{\star}$ \\
\hline Salami & 0 & 20 & 2 & 31 & $0.00(0.00,8.82)$ & $0.52^{\star}$ \\
\hline \multicolumn{7}{|l|}{ Any delicatessen } \\
\hline product & 14 & 3 & 13 & 14 & $5.03(1.01,32.3)$ & 0.05 \\
\hline Meat pie & 2 & 18 & 11 & 23 & $0.23(0.02,1.30)$ & $0.10^{\star}$ \\
\hline Meat pastie & 2 & 18 & 8 & 26 & $0.36(0.03,2.15)$ & $0.29^{\star}$ \\
\hline Sausage roll & 2 & 18 & 8 & 26 & $0.36(0.03,2.15)$ & $0.29^{\star}$ \\
\hline Eggs & 9 & 11 & 26 & 8 & $0.25(0.07,0.96)$ & 0.04 \\
\hline Mayonnaise & 8 & 12 & 10 & 24 & $1.60(0.42,5.90)$ & 0.62 \\
\hline Ice cream & 6 & 14 & 27 & 7 & $0.11(0.03,0.46)$ & 0.0009 \\
\hline Yoghurt & 9 & 11 & 16 & 18 & $0.92(0.26,3.20)$ & 0.89 \\
\hline
\end{tabular}

^Two tailed Fisher's exact test.

\section{KEY POINTS}

- Foodborne community outbreaks are difficult to investigate if recognition is delayed, cases are geographically scattered or the cause is a common food item.

- Sequential case-control studies are particularly efficient in these circumstances and deserve to be more widely used.

- An initial broad and inclusive case definition is used and refined as the investigation proceeds to increase its specificity.

- The first study is used to identify the food vehicle and the second to identify the specific brand or batch number.

- The precision of the second stage can be extremely powerful.

about ham supply, storage, and preparation procedures. If the store had bought ham from a distributor, the distributor was contacted and asked about the original ham source and details of ham preparation procedure.

Data analysis was carried out using Epi Info Version $69^{9}$ Food preference tables were constructed and differences in categorical variables tested using Mantel-Haenszel $\chi^{2}$ with Yates's correction or two tailed Fisher's exact test. Univariate odds ratios were calculated with exact $95 \%$ confidence intervals (CI). ${ }^{10}$

Retail store and distributor premises were inspected by environmental health officers to determine whether the food hygiene standards and food preparation practices were satisfactory. The main distributor, producer A, was visited and specific inquiries made about any problem with ham production or change in cooking procedure that may have arisen during April or May. Samples of sliced ham on sale at the retail stores visited, and samples of recently cooked ham joints and drain swabs from producer A were submitted for microbiological examination.

\section{Results}

Preliminary interviews were completed for six men and six women aged from 14 months to 58 years, all of whom had become ill during May. Although cases were scattered throughout south east Wales, there was some geographical clustering. None of the cases had recently been abroad. All 11 primary cases had eaten cold meats and 10 had eaten sliced, pre-cooked ham purchased from local retail stores.

STAGE 1 CASE-CONTROL STUDY

Twenty of 28 confirmed cases were interviewed. Three cases could not be contacted, one case had died, and the remaining four were secondary cases. Dates of onset of symptoms ranged from 3 to 24 May (fig 1). Thirteen cases were men and mean age was 31.9 years (range 1-77). The most common symptoms described by cases were diarrhoea (19 of 20 cases), abdominal pain (18 of 20 cases), and 
Table 2 Case-control study 2. Association between illness and type of ham consumed by cases and controls in a salmonella outbreak in south east Wales, 1992

\begin{tabular}{|c|c|c|c|c|c|c|}
\hline \multirow[b]{2}{*}{ Food item } & \multicolumn{2}{|c|}{ Case $(n=16)$} & \multicolumn{2}{|c|}{ Control $(n=16)$} & \multirow[b]{2}{*}{ Odds ratio $(95 \%$ CI) } & \multirow[b]{2}{*}{$p$ Value * } \\
\hline & Ate & Not ate & Ate & Not ate & & \\
\hline \multirow{2}{*}{$\begin{array}{l}\text { Sliced ham from local store } \\
\text { Sliced ham from store supplied by } \\
\text { producer A }\end{array}$} & 12 & 4 & 4 & 12 & $9.00(1.46,60.6)$ & 0.012 \\
\hline & 10 & 6 & 1 & 15 & $25.00(2.33,1155)$ & 0.002 \\
\hline
\end{tabular}

^Two tailed Fisher's exact test.

fever (14 of 20 cases). Other symptoms included nausea ( 10 of 20 ), vomiting ( 5 of 20 ), and drowsiness ( 3 of 20 ). Two cases required hospital admission, of whom one died (salmonella septicaemia and a cerebrovascular accident).

Thirty four controls were interviewed, the remainder could not be contacted despite several attempts. Because of the shortfall in matched pairs the matching was not preserved in the analysis and data handled as group matched rather than individually matched. Consumption of any cold sliced meat, cold sliced ham, and shopping at a delicatessen were all associated with increased risk of illness (table 1). Sixteen of 20 cases compared with 16 of 34 controls had eaten ham within three days of onset of illness (odds ratio $(\mathrm{OR})=4.50,95 \%$ CI 1.10, 21.8).

STAGE 2 CASE-CONTROL STUDY

Of the 16 cases and 16 controls who had eaten ham, 12 cases compared with four controls had bought the ham from a small, local store (rather than a large superstore) $(\mathrm{OR}=9.00$, $95 \%$ CI 1.46, 60.6, $\mathrm{p}=0.012$ ). The 12 cases who had eaten ham bought from a local store identified 20 different stores from which ham had been purchased. However, 10 of 12 cases had bought ham from stores supplied by a common wholesaler-producer A. By contrast, only one of four controls had eaten ham from a local store supplied by this producer (table 2). The association between illness and the consumption of ham originating from producer A was highly significant (OR $=25.0$, 95\% CI 2.33, 1155, $\mathrm{p}=0.002)$.

Producer A was a small combined distributor and retailer. The premises comprised a retail store at the front with a food preparation room behind. None of the staff involved in ham preparation had undertaken any food hygiene training. Raw pork joints, imported from Europe, were delivered to the premises three times a week. Joints were boned and mechanically injected with curing solution before being placed in tanks of brine for three days. Curing tanks were hosed down between use but seldom disinfected. Cured joints weighing around $7 \mathrm{~kg}$ were sealed in cooking bags using metal ties, steam cooked for eight hours at a temperature of $86^{\circ} \mathrm{C}$, and cooled using cold water showers. Batches of around 70 ham joints were cooked at a time. After cooling, the ham was placed on a meat preparation table to remove the cooking bag, jelly, and fat. It was then vacuum packed and stored in a refrigerated room before distribution by refrigerated van. The ham had a shelf life of several weeks.
Repeated close questioning of producer $\mathrm{A}$ failed to identify any oven or refrigerator breakdown problems. However, after several visits by investigators, the producer admitted changing his usual ham cooking procedure as an economy measure after receiving a large bill for water supplies in April. Instead of cooling hams in the usual way, the joints had been removed from the oven while still hot and placed overnight in cold water in two tanks normally reserved for curing raw pork. This cooling method had been used on only one occasion as it was not deemed a success, as the ham took too long to cool. No residual ham from the implicated batch was available for microbiological analysis, but all ham samples obtained from retail stores and samples of recently cooked ham and drain swabs from producer A tested negative.

\section{Discussion}

This outbreak investigation shows the value of a sequential case-control study method for establishing the source of a community salmonella outbreak caused by a common food item even when some time after the incident has elapsed. After confirming the initial hypothesis that sliced cooked ham was the vehicle of infection, the source was traced to a single distributor. Detailed environmental investigation then identified a breakdown in ham preparation procedures, which probably allowed cross contamination between raw pork and cooked ham and incubation of contaminated ham in a warm water bath overnight. The staged approach permitted gradual refining of the hypothesis and avoided the need for a cumbersome and inefficient investigation to obtain multiple details on all possible hypotheses at the outset.

Several forms of bias can affect the results of a case-control study of which the most pertinent in the context of outbreak investigation are selection bias (for example, nonparticipation bias), interviewer bias, and recall bias. ${ }^{11}$ Non-participation bias was limited in this study by making strenuous efforts to contact all cases and controls, although the participation rate for controls was less than that for cases. It is also important to minimise the influence of the interviewer on answers elicited from both cases and controls although it is seldom possible to use blind interviewers in field investigations. In this study, experienced interviewers used the same structured questionnaire for all subjects to ensure compatibility of information collected. Recall bias is a particular problem in outbreak investigation because considerable time may elapse between onset of 
illness, recognition of the outbreak, and conduct of the investigation. Delay in recognition of outbreaks is likely to be worse if numbers of cases are small, widely scattered in time or place, or the disease is caused by a common organism (thus requiring detailed typing to identify the outbreak strain), as in the outbreak we describe. The validity of the results may be affected if differential recall occurs in cases compared with controls. To limit this possibility, the hypothesis under test in the study was not publicised and the interviewers placed no particular emphasis on ham consumption. Similar questions were asked of all cooked meats, but none of the other cooked meats showed any association with illness. Only 12 of 20 cases could be linked with consumption of ham from a local store because many ham consumers could not remember the exact place of purchase, and some stores did not have accurate details of ham suppliers. However, inclusion of cases from the initial descriptive study in the case-control study may have overestimated the association between illness and eating ham because of greater effort on the part of cases to remember past exposures.

A number of outbreak investigations have shown the usefulness of sequential case-control studies in identifying unusual vehicles of infection or low level contamination in a nationally distributed product, although these have almost exclusively been reported from the United States. ${ }^{12-14}$ In a multistate outbreak of $S$ muenchen, an initial case-control study failed to implicate a food source, but found that all case households included persons 15 to 35 years old compared with less than half of control households. ${ }^{12}$ Marijuana use was subsequently identified as the cause of the outbreak by a second case-control study and confirmed by plasmid fingerprinting of $S$ muenchen isolates from marijuana samples. Another multistate outbreak involving $S$ javiana and $S$ oranienburg was initially traced to contaminated cheese, but only after a second case-control study entailing more detailed questioning was the type, brand, and production plant of the cheese identified, and then confirmed as the source by microbiological analysis. ${ }^{13}$ Similarly, an unusual vehicle of infection responsible for the Illinois botulism outbreak was only identified after two sequential case-control studies. ${ }^{14}$ In the first stage of the investigation, patty-melt sandwiches obtained from the same restaurant were identified as the common food vehicle. However, a second case-control study using fresh controls who had also eaten patty-melt sandwiches (recruited by means of a media appeal) was required to pin-point the sautéed onions as the sandwich component responsible. Type A Clostridium botulinum was subsequently cultured from raw onions taken from the restaurant.

A similar approach has been used in non-communicable disease outbreaks. In an outbreak of thyrotoxicosis caused by consumption of bovine thyroid gland, two case-control studies were performed after first defining the temporal and geographical boundaries of the outbreak by case surveillance. ${ }^{15}$ The first study found that illness was associated with eating certain meat or poultry products, but a second study was required to identify the exact source of the suspect products. Ground beef samples from the implicated production plant and grocery store outlets were found to contain high concentrations of thyroid hormones. The eosinophilia-myalgia syndrome was linked with tryptophan use after a case-control investigation, but a second case-control study was necessary to pin point the brand and retail lot numbers of the tryptophan responsible. ${ }^{16}$ This was subsequently confirmed by chemical analysis of the implicated tryptophan brand. Rapid epidemiological investigation thus led to early containment measures and prevented further public exposure to the causative agent. ${ }^{17}$

Case-control studies are now a well established tool in outbreak investigation, ${ }^{3-5}$ and methods of analysis are becoming more sophisticated. ${ }^{18}$ What is less well appreciated is that sequential case-control studies may sometimes be necessary to clarify and refine the hypothesis under test. A broad and inclusive case definition is used initially, but this can be refined as the investigation proceeds to increase its specificity. For instance, the first stage may identify the vehicle of infection but the second stage is used to identify the specific brand or batch number. In the second stage, there is a clear shift in definition of cases and controls who are usually restricted to those exposed to the suspect vehicle identified in the first stage. Re-defined cases and controls may be drawn from those included in the first study (sequential interview) or may be sampled afresh. However, if there are several possible brands involved, this approach may not allow calculation of an odds ratio for each brand. In this instance, cases and controls may be investigated whether or not they were exposed to the suspect vehicle of infection and an odds ratio calculated for each brand with reference to absence of exposure to the vehicle. This allows calculation of a comparable odds ratio for each brand.

The case-control design is the most efficient in circumstances where multiple hypotheses require evaluation as new hypotheses may be advanced during the course of the investigation and the study adapted as necessary. It is particularly appropriate in the absence of microbiological evidence of food contamination when a highly specific hypothesis is necessary to provide satisfactory, plausible, epidemiological evidence of causation. The precision of the second stage can be extremely powerful but depends on collecting data on the source of foods eaten by both cases and controls, a principle not always appreciated by the regulatory authorities who may be involved in the traceback process. The outbreak investigation we describe shows that even when primary microbiological methods cannot be used, the case-control method can still be successful. It is also an example of consequential epidemiology. By defining the most probable sequence of events leading to the outbreak, a 
poor practice was identified at producer level that could be prevented in future.

The authors are indebted to Miss Sharon Powell and Mr Dennis Gardner of Cardiff Environmental Services, Mrs Kath Taber of the Vale of Glamorgan Environmental Health Department,
and Dr Don Ribeiro of Cardiff Public Health Laboratory for their contribution to the outbreak investigation.

1 Bean NH, Griffin PM, Goulding JS, et al. Foodborne disease outbreaks, 5-year summary, 1983-1987. In: Waltham, Massachusetts: $C D C$ surveillance sum

2 Cowden JM, Wall PG, Adak G, et al. Outbreaks of foodborne infectious intestinal disease in England and Wales. Commun Dis Rep 1995;5:R109-17.

3 Palmer SR. Epidemiology in infectious diseases: methods in outbreak investigation. $\mathcal{F}$ Epidemiol Community Health 1989;43:311-14.

4 Goodman RA, Buehler JW, Koplan JP. The epidemiologic field investigation: science and judgment in public health practice. Am F Epidemiol 1990;132:9-15.

5 Dwyer DM, Strickler H, Goodman RA, et al Use of casecontrol studies in outbreak investigations. Epidemiol Rev 1994;16:109-23.

6 Anon. Salmonella typhimurium DT 124. Commun Dis Rep 1992;2:111.

7 Cowden JM, O'Mahony M, Bartlett CLR, et al. A national outbreak of Salmonella typhimurium DT 124 caused by contaminated salami sticks. Epidemiol Infect 1989;103:21925.

8 Palmer SR, Henry R. EPINET in Wales: PHLS Cadwyn Cymru. Development of a public health information system. Public Health Laboratory Service Microbiology Digest 1992;9:107-9.

9 Dean AG, Dean JA, Coulombier D, et al. Epi Info Version 6: a word processing database and statistics program for epidemiology on microcomputers. Atlanta, Georgia: Centers for Disease Control and Prevention, 1994.

10 Breslow NE, Day NE. Statistical methods in cancer research. Vol 1. The analysis of case-control studies. Lyons: International Agency for Research on Cancer, 1980: sections 4.2 and 4.3.

11 Austin H, Hill HA, Flanders D, Greenberg RS. Limitations in the application of case-control methodology. Epidemiol Rev 1994;16:65-76.

12 Taylor DN, Wachsmuth IK, Shangkuan Y-H, et al. Salmonellosis associated with marijuana: a multistate outbreak traced by plasmid fingerprinting. $N$ Engl f Med 1982;306:1249-53.

13 Hedberg CW, Korlath JA, D'Aoust J-Y, et al. A multistate outbreak of Salmonella javiana and Salmonella oranienburg infections due to consumption of contaminated cheese. F $A M A$ 1992;268:3203-7.

4 MacDonald KL, Spengler RF, Hatheway CL, et al. Type A botulism from sautéed onions. FAMA 1985;253:1275-8.

15 Hedberg CW, Fishbein DB, Janssen RS, et al. An outbreak of thyrotoxicosis caused by the consumption of bovine thyroid gland in ground beef. $N$ Engl $\mathcal{F}$ Med 1987;316:993-8.

16 Belongia EA, Hedberg CW, Gleich GJ, et al. An investigation of the cause of the eosinophilia-myalgia syndrome associated with tryptophan use. N Engl f Med 1990;323: 357-65.

17 Taylor R, McNeil JJ. Eosinophilia-myalgia syndrome: lessons for public health researchers. Med f Aust 1993;158: $51-5$.

18 Fonseca MGP, Armenian HK. Use of the case-control method in outbreak investigations. $A m \mathcal{F}$ Epidemiol 1991;133:748-52. 